\title{
The Effect of Endometriosis Symptoms on Absenteeism and Presenteeism in the Workplace and at Home
}

\author{
Ahmed M. Soliman, MS, PhD; Karin S. Coyne, MPH, PhD; Katharine S. Gries, PharmD, PhD; \\ Jane Castelli-Haley, PhD; Michael C. Snabes, MD, PhD; and Eric S. Surrey, MD
}

\begin{abstract}
BACKGROUND: Characterized by pain symptoms, endometriosis affects women's productivity in their prime working years.

OBJECTIVE: To evaluate the effect of individual endometriosis symptoms on household chore and employment productivity as measured by presenteeism and absenteeism in a population survey of women with endometriosis.

METHODS: An online survey of U.S. women was conducted to evaluate the prevalence of endometriosis, as well as symptoms, demographics, and clinical characteristics of the respondents. Women aged 18-49 years (inclusive) with endometriosis completed the Health-related Productivity Questionnaire to assess presenteeism and absenteeism for employed and household work. Descriptive statistics were used to describe the sample, survey responses, and the effect of endometriosis symptom severity on household chore and employment productivity. Regression analyses were performed to examine the effect of individual endometriosis symptoms on employment and household productivity lost because of presenteeism and absenteeism.
\end{abstract}

RESULTS: Of 59,411 women who completed the prevalence screener, 5,879 women $(9.9 \%)$ met the inclusion criteria for completing the survey; 1,318 women $(2.2 \%)$ reported endometriosis and at least 1 hour of scheduled household chores in the past 7 days. Of these, 810 women had least 1 hour of scheduled employment in the past 7 days. Mean age was 34.6 years (standard error $[\mathrm{SE}] \pm 0.32$ ); $77.2 \%$ of the women were white; $59.3 \%$ were married or in a civil union; and $59.1 \%$ were employed full or part time. Women with endometriosis had a weekly loss of an average of 5.3 hours $(S E \pm 0.4)$ because of employment presenteeism, 1.1 hours ( $\mathrm{SE} \pm 0.2$ ) of employment absenteeism, $2.3(\mathrm{SE} \pm 0.2)$ hours of household presenteeism, and $2.5(\mathrm{SE} \pm 0.2)$ hours of household absenteeism. Hourly losses in employment and household chore productivity were significantly greater with increasing symptom severity (mild vs. severe: 1.9 vs. 15.8 total employment hours lost and 2.5 vs. 10.1 total household hours lost; $P<0.0001)$. Women who experienced 3 endometriosis symptoms concurrently lost a significantly greater number of employment hours because of absenteeism and presenteeism compared with those experiencing 1 or 2 symptoms $(P<0.001)$. Regression analyses showed that a range of endometriosis symptoms predicted employment and household losses because of presenteeism and absenteeism.

CONCLUSIONS: There was a significant relationship between the number and patient-reported severity of endometriosis symptoms experienced and hours of employment and household productivity lost because of presenteeism and absenteeism. Study findings indicate a need for guidance strategies to help women and employers manage endometriosis so as to reduce productivity loss.

J Manag Care Spec Pharm. 2017;23(7):745-54

Copyright $\odot 2017$, Academy of Managed Care Pharmacy. All rights reserved.

\section{What is already known about this subject}

Endometriosis is a chronic condition that affects women in their prime working years (30s and 40s) and affects around 10\% of women worldwide.

Since endometriosis is characterized by pain symptoms, it has been shown to have a significant negative effect on women's health-related quality of life, as well as their productivity.

\section{What this study adds}

This study is the first to demonstrate the association of individual endometriosis symptoms and employment and household chore productivity as measured by absenteeism and presenteeism in a population survey of women with endometriosis.

There is a significant relationship between the number and patient-reported severity of endometriosis symptoms experienced and the effect on hours of employment and household chore productivity lost overall.

Study findings indicate a need for guidance strategies to help women and employers manage endometriosis so as to reduce productivity loss.

$\square$ ndometriosis is a condition in which the lining of the uterus grows outside of the uterus. It is common in women in their 30s and 40s and affects approximately $10 \%$ of women worldwide, including 7 million American women, ${ }^{1}$ with a reported prevalence between $2 \%$ and $17 \%$ of the general female population. ${ }^{2,3}$ The condition is characterized by symptoms such as painful menstrual cramps, pain in the lower back and pelvis, pain during or after sex, intestinal pain, painful bowel movements or pain when urinating during menstrual periods, bleeding or spotting between menstrual periods, and digestive problems (i.e., diarrhea, constipation, bloating, or nausea). ${ }^{4}$ Infertility is also common; Fourquet et al. (2010) found that of $71 \%$ of women with endometriosis who had attempted to conceive, 90\% had experienced difficulties. ${ }^{5}$

Research on endometriosis has shown that the condition and associated symptoms can have a significant negative effect on a woman's personal, physical, psychological and social wellbeing, and health-related quality of life (HRQoL). 2,4,6,7 Many women may find it difficult to carry out their normal everyday tasks and activities. In a recent review, Culley et al. (2013) 
found that between $23 \%$ and $71 \%$ of women with endometriosis reported that their condition had a significant effect on their household activities such as cooking, shopping, cleaning, and child care. ${ }^{2}$

Using a cross-sectional survey with Puerto Rican women, Fourquet et al. found that endometriosis-related and coexisting symptoms disrupted all aspects of women's daily lives, including physical limitations that affected doing household chores and paid employment. ${ }^{5}$ The majority of women (85\%) experienced a decrease in the quality of their work; $20 \%$ reported being unable to work because of pain, and over two-thirds of the sample continued to work despite their pain. Over twothirds of the sample $(60 \%)$ reported missing a mean of 2.8 days per month (standard deviation $[S D] \pm 3.7 ; 33.6$ days/year), and an average of 19.3 work days ( $S D \pm 19.3$ ) were missed because of endometriosis-related treatments, surgeries, and recovery. Other work-related areas, such as career growth and promotion were also affected. In a similar survey, women reported an average of 7.4 hours ( 1 working day) of work time lost during the past 7 days when their symptoms were at their worst. ${ }^{1}$

The Global Study of Women's Health was conducted in 16 hospitals in 10 countries to assess the effect of endometriosis on HRQoL and work productivity. ${ }^{8-10}$ Greater absenteeism (missed time from work) and presenteeism (reduced productivity while at work) were reported by women with endometriosis compared with control women without endometriosis. Overall work productivity loss for the former group was 10.8 hours per week $(\mathrm{SD}=12.2)$ and 8.4 hours per week $(\mathrm{SD}=10.2)$ for the latter. Absenteeism $(P=0.019)$, presenteeism $(P=0.033)$, and overall work productivity loss $(P=0.014)$ increased with increasing disease severity (measured using the revised American Fertility Society classification). Costs related to absenteeism and presenteeism ranged widely across the participating countries, from $\$ 1$ per week in Nigeria to $\$ 231$ per week in Italy, and from $\$ 3$ per week in Nigeria to $\$ 250$ per week in the United States, respectively (all costs given in U.S. dollars). Other studies reported a similar pattern of findings. $3,4,6,11,12$

Research has shown that endometriosis-related symptoms have a negative effect on work productivity and general HRQoL. The findings of an international, multicenter questionnaire-based survey showed that the presence of symptoms such as menstrual pain, incapacitating pain, abdominal pain, pelvic pain, and infertility may predict poor performance at work. ${ }^{13}$ Length of time living with endometriosis, receiving treatment for the condition, and comorbid conditions, such as depression, may also play a significant role in predicting work impairment. ${ }^{5,13}$

Reduced effectiveness at work (presenteeism) may account for greater loss of work productivity than time absenteeism. ${ }^{11}$ The yearly total (direct plus indirect) cost of endometriosis has been estimated at $€ 30$ billion in Europe and $\$ 22$ billion in the United States. ${ }^{5}$ Simoens et al. (2012) reported that average costs of productivity loss per woman with endometriosis is estimated to be $€ 6,298$, which is double the average direct health care cost. ${ }^{14}$ Direct and indirect costs across individual countries have also been reported. ${ }^{11,15-21}$

Despite the evidence that endometriosis has a significant effect on productivity, little work has been conducted to examine the effect of individual symptoms and symptom severity on employment and household chore productivity of U.S. women diagnosed with endometriosis. Therefore, this study was conducted to evaluate the effect of individual endometriosis symptoms on employment and household chore productivity as measured by absenteeism and presenteeism in a population survey of women with endometriosis. A similar analysis that examines the effect of uterine fibroids symptoms on healthrelated productivity losses will be reported later.

\section{Methods}

\section{Study Design}

Data were from a cross-sectional web-based survey conducted among the general population of women in 5 countries (United States, Japan, China, Russia, and Brazil) from August to September 2012. The survey explored the prevalence, symptomatic burden, economic and productivity burden, and HRQL of endometriosis and uterine fibroids as described in previous studies. $^{22,23}$ This study limits its focus to the symptomatic burden of endometriosis on health-related productivity among women enrolled in the United States.

Recruitment aimed to include a representative sample of the general female population, while identifying and reaching underrepresented populations. This study was reviewed and approved by the Copernicus Group Institutional Review Board.

\section{Study Sample and Data Collection}

The study sample was composed of women from the Harris Poll Online, Global Market Insite and E-rewards panels. Information regarding these panels has been previously published. ${ }^{22,23}$ Women in the targeted sample pool received an e-mail invitation describing the study in general terms. The e-mail directed those interested to a survey website housed on secure servers.

Women were considered eligible to complete the Healthrelated Productivity Questionnaire (HRPQ) survey if they were aged between 18 and 49 years, had been diagnosed with endometriosis, were symptomatic, were being treated for endometriosis, or had a hysterectomy. All respondents were asked this question: "Has a doctor ever told you that you have or are suspected of having any of the following health conditions? Please select all that apply." The 32 response choices included "endometriosis," "uterine fibroids," and "none of these," as well as a variety of different health conditions. To identify women with symptomatic endometriosis, participants were asked if they had ever experienced any of the following symptoms 


\begin{tabular}{|c|c|c|c|c|c|}
\hline & $\begin{array}{c}\text { All } \\
\begin{array}{c}\text { Participants } \\
(\mathrm{n}=1,318)\end{array}\end{array}$ & $\begin{array}{c}\text { Employed } \\
\text { Participants } \\
(\mathrm{n}=810)\end{array}$ & & $\begin{array}{c}\text { All } \\
\text { Participants } \\
(\mathrm{n}=1,318)\end{array}$ & $\begin{array}{c}\text { Employed } \\
\text { Participants } \\
(\mathrm{n}=810)\end{array}$ \\
\hline Age, mean $( \pm$ SE) & $34.6 \quad(0.3)$ & $35.2(0.4)$ & \multicolumn{3}{|l|}{ Education level, n (\%) } \\
\hline \multicolumn{3}{|l|}{ Age range, years, $\mathrm{n}(\%)$} & Graduate education & $301(14.2)$ & $222(17.3)$ \\
\hline $18-29$ & $326(31.1)$ & $178(28.0)$ & \multicolumn{3}{|l|}{ Employment, n (\%) } \\
\hline $30-34$ & $278(23.9)$ & $174(23.5)$ & Employed full time & $610(43.1)$ & $602(73.8)$ \\
\hline $35-39$ & $234(14.7)$ & $154(15.9)$ & Employed part time & $150(10.9)$ & $141(18.1)$ \\
\hline $40-44$ & $249(15.2)$ & $165(17.8)$ & Self-employed & $74 \quad(5.1)$ & $67 \quad(8.2)$ \\
\hline $45-49$ & $231(15.2)$ & $139(14.8)$ & Not employed but looking for work & $95 \quad(9.2)$ & - \\
\hline Average age at diagnosis, years (SE) & $25.9 \quad(0.3)$ & $26.8 \quad(0.4)$ & Not employed and not looking for work & $12(1.0)$ & - \\
\hline \multicolumn{3}{|l|}{ Diagnostic method, n (\%) } & Not employed unable to work because of & $(0.1)$ & - \\
\hline Empirical & $566(43.9)$ & $346(42.9)$ & disability or illness & & \\
\hline Patient report & $58 \quad(4.2)$ & $34 \quad(3.8)$ & Retired & $65 \quad(5.0)$ & - \\
\hline Surgical & $694(51.9)$ & $430(53.3)$ & Student & $57 \quad(4.5)$ & - \\
\hline \multicolumn{3}{|l|}{ Race, n (\%) } & Stay-at-home partner/housewife & $253(21.2)$ & - \\
\hline White/Caucasian & $1,120(77.2)$ & $686(78.0)$ & Height, inches, mean $( \pm$ SE) & $65.0 \quad(0.1)$ & $65.2(0.1)$ \\
\hline Black & $47 \quad(5.4)$ & $26 \quad(4.7)$ & Weight, pounds, mean $( \pm$ SE) & $167.5 \quad(2.0)$ & $167.5(2.7)$ \\
\hline Other & $151(17.3)$ & $98(17.2)$ & Body mass index, mean $( \pm S E)$ & $27.8 \quad(0.3)$ & $27.7 \quad(0.4)$ \\
\hline \multicolumn{3}{|l|}{ Marital status, n (\%) } & \multicolumn{3}{|l|}{ Pregnant, n (\%) } \\
\hline Never married & $272(19.7)$ & $178(19.8)$ & I am currently pregnant & $39 \quad(4.1)$ & $17 \quad(3.1)$ \\
\hline Married or civil union & $761(59.3)$ & $444(59.4)$ & I am actively trying to become pregnant & $133(12.0)$ & $90(14.5)$ \\
\hline Divorced & $107 \quad(7.0)$ & $78 \quad(8.3)$ & I am not currently trying to become pregnant & $517(39.7)$ & $318(39.1)$ \\
\hline Separated & $31 \quad(2.8)$ & $18 \quad(2.1)$ & No desire to get pregnant at any point in the & $597(41.8)$ & $367(41.0)$ \\
\hline Widow/widower & $11 \quad(0.7)$ & $8 \quad(0.6)$ & future & & \\
\hline Living with partner & $127 \quad(9.9)$ & $77 \quad(8.9)$ & Not sure & $28 \quad(2.1)$ & $16 \quad(2.2)$ \\
\hline Decline to answer & $9 \quad(0.6)$ & $7 \quad(1.0)$ & Decline to answer & $(0.3)$ & $2(0.2)$ \\
\hline \multicolumn{3}{|l|}{ U.S. region, n (\%) } & \multicolumn{3}{|l|}{ Insurance type, n (\%) } \\
\hline Midwest & $343(25.3)$ & $222(27.0)$ & Public & $155(12.4)$ & $80(10.6)$ \\
\hline Northeast & $248(18.8)$ & $145(19.0)$ & Private & $859(61.5)$ & $617(74.7)$ \\
\hline South & $473(35.3)$ & $288(34.3)$ & Other & $134(11.2)$ & $35 \quad(3.9)$ \\
\hline West & $254(20.6)$ & $155(19.8)$ & None & $170(15.0)$ & $78(10.8)$ \\
\hline \multicolumn{3}{|l|}{ Education level, n (\%) } & \multicolumn{3}{|l|}{ Number of symptoms experienced } \\
\hline High school or less & $138(19.0)$ & $48(10.6)$ & Overall symptoms, mean $( \pm$ SE) & $5.1 \quad(0.1)$ & $4.9 \quad(0.1)$ \\
\hline Some college/college & $879(66.7)$ & $540(72.1)$ & Endometriosis symptoms, mean $( \pm \mathrm{SE})$ & $1.5(0.03)$ & $1.5(0.04)$ \\
\hline
\end{tabular}

of endometriosis over the past 4 weeks and to select all that applied: pelvic pain/cramping during menstrual period, pelvic pain during nonmenstrual period days, and pain during sex.

\section{Patient Survey}

The patient survey included standardized questions, as well as questions developed for this study. Participants were asked to provide demographic information and clinical characteristics (symptoms and comorbidities). To rate the severity of individual symptoms, participants were asked, "Please rate the level of severity for any symptoms you have experienced within the past month," and answer options were either "have not had the symptom in the past month," "mild," "moderate," or "severe." To rate overall severity of endometriosis symptoms, participants were asked, "How would you categorize the overall severity of your endometriosis symptoms?" Response options were "mild," "moderate," and "severe."
The HRPQ is a 9-item measure of productivity, including absenteeism (work time missed, including household work) and presenteeism (reduced work effectiveness because of endometriosis, including household work). ${ }^{24}$ The HRPQ was modified to be specific to endometriosis by asking women the question "Did endometriosis or its treatment keep you from working any of your scheduled hours in the past 7 days?" and was administered to assess current productivity loss using a 1-week recall period. The HRPQ includes items on mean scheduled work hours; employment productivity lost because of absenteeism and presenteeism; hours of lifetime productivity lost because of illness effects on workforce participation; planned household work hours (examples provided in the survey question included cooking, cleaning, gardening, and repairs); and household productivity lost because of absenteeism and presenteeism. The HRPQ was scored according to the developer's algorithm. 


\begin{tabular}{|c|c|}
\hline $\begin{array}{cc}\text { TABLE } 2 \text { Productivity Losses Mea } \\
\text { Health-Related Productiv }\end{array}$ & $\begin{array}{l}\text { ed by } \\
\text { Questionnaire }\end{array}$ \\
\hline $\begin{array}{l}\text { Effect on Household Chores } \\
\text { (All Participants) }\end{array}$ & $\begin{array}{c}\text { Frequency } \\
(\text { Mean } \pm \text { SE/ } \\
\text { Percentage) } \\
\mathbf{n}=1,318\end{array}$ \\
\hline Hours of planned household work in previous week & $15.6 \pm 0.5$ \\
\hline \multicolumn{2}{|l|}{ Hours of household productivity lost } \\
\hline Total hours & $4.9 \pm 0.4$ \\
\hline Absenteeism & $2.5 \pm 0.2$ \\
\hline Presenteeism & $2.3 \pm 0.2$ \\
\hline \multicolumn{2}{|l|}{ Percentage of household productivity lost } \\
\hline Total percentage of hours & $27.9 \pm 1.4$ \\
\hline Absenteeism & $15.2 \pm 1.1$ \\
\hline Presenteeism & $12.7 \pm 0.7$ \\
\hline Effect on Employment (Employed Participants) & $\begin{array}{c}\text { Frequency } \\
(\text { Mean } \pm \text { SE/ } \\
\text { Percentage) } \\
\mathbf{n}=810\end{array}$ \\
\hline \multicolumn{2}{|l|}{ Hours of scheduled work in previous week } \\
\hline For all participants & $37.7 \pm 0.6$ \\
\hline For full-time employed participants $(n=643)$ & $41.4 \pm 0.6$ \\
\hline For part-time employed participants $(\mathrm{n}=167)$ & $23.2 \pm 1.3$ \\
\hline \multicolumn{2}{|l|}{ Hours of employment productivity lost } \\
\hline Total hours & $6.3 \pm 0.6$ \\
\hline Absenteeism & $1.1 \pm 0.2$ \\
\hline Presenteeism & $5.3 \pm 0.4$ \\
\hline \multicolumn{2}{|l|}{ Percentage of employment productivity lost } \\
\hline Total percentage of hours & $16.9 \pm 1.3$ \\
\hline Absenteeism & $2.9 \pm 0.5$ \\
\hline Presenteeism & $14.0 \pm 1.0$ \\
\hline
\end{tabular}

\section{Statistical Analysis}

Analyses were performed using SAS version 9.3 (SAS Institute, Cary, NC). The data were analyzed as observed, without imputation for missing responses. The data were weighted using the Random Iterative Method (RIM) as described in a previous study. ${ }^{22}$ Descriptive statistics were used to describe the sample, survey responses, and effect of endometriosis symptom severity on household chore and employment productivity. For continuous variables, the mean and standard error were calculated, and for categorical variables, the number and percentage distribution were presented. Independent-sample t-tests and one-way between groups analysis of variance tests were conducted to examine the associations between the severity of symptoms (none/mild vs. moderate/severe), overall severity of endometriosis, number of concurrently experienced endometriosis symptoms, and productivity losses.

Multivariate logistic regressions were performed to examine the effect of individual endometriosis symptoms on the likelihood of employment and household chore productivity loss because of absenteeism and presenteeism as a dichotomous dependent variable (loss vs. no loss). Model covariates included age; ethnicity (white/Caucasian, black/African American, and others); education (high school or less, some college/college, and graduate education); U.S. region (Midwest, Northeast, South, and West); marital status; body mass index; endometriosis symptoms; and comorbid conditions (i.e., diabetes, irritable bowel disease or inflammatory bowel disease, fibromyalgia, ovarian cysts, depression, hypertension, chronic fatigue syndrome, and interstitial cystitis).

\section{Results}

\section{Participant Demographics}

A total of 382,797 U.S. panel members were contacted to participate in the survey. Of those, 59,411 women (15.5\%) completed the prevalence screener; 5,879 (9.9\%) women met the inclusion criteria for completing the survey, with 1,318 (2.2\%) women reporting endometriosis and at least 1 hour of scheduled household chores in the past 7 days. Of these, 810 participants had least 1 hour of scheduled employed work in the past 7 days.

The mean age of the overall sample was 34.6 years (standard error [SE] 0.32); the majority of the sample was white (77.2\%); and more than half were married or in a civil union (59.3\%). Most women were employed, either full time (43.1\%), part time (10.9\%), or identified as self-employed (5.1\%). A small percentage of participants were currently pregnant (4.1\%), and $12.0 \%$ were actively trying to become pregnant (Table 1).

\section{Participant Symptoms and Comorbidities}

Among women with endometriosis, the most commonly reported symptoms experienced by patients in the past 4 weeks were anxiety/stress (73.6\%), pelvic pain/cramping during menstrual period $(72.7 \%)$, lower back pain $(70.9 \%)$, fatigue/weariness/anemia (69.9\%), bloating (64.9\%), and depression feelings/ mood swings (64.9\%). The following symptoms were the most frequent moderate/severe symptoms for employed women: pelvic pain/cramping during menstrual period (54.9\%), fatigue/ weariness/anemia (46.7\%), anxiety/stress (46.5\%), and lower back pain (41.8\%; Appendix A, available in online article). Similar findings were reported for all women, including women who were not employed.

The most frequently reported comorbid conditions by all women and the employed subgroup were ovarian cysts (43.7\% and $41.0 \%$ ), depression ( $41.7 \%$ and $35.4 \%$ ), anemia (33.0\% and $29.6 \%$ ), obesity ( $21.6 \%$ and $21.5 \%$ ), and irritable bowel disease or inflammatory bowel disease (21.2\% and $19.9 \%)$. A significant proportion of the total sample (29.6\%) and the employed sample (32.6\%) did not report experiencing any comorbid conditions. 


\section{FIGURE 1 Employment-Related Productivity Hours Lost Across Different Patient-Reported Severity Levels of} Currently Experienced Endometriosis Symptoms

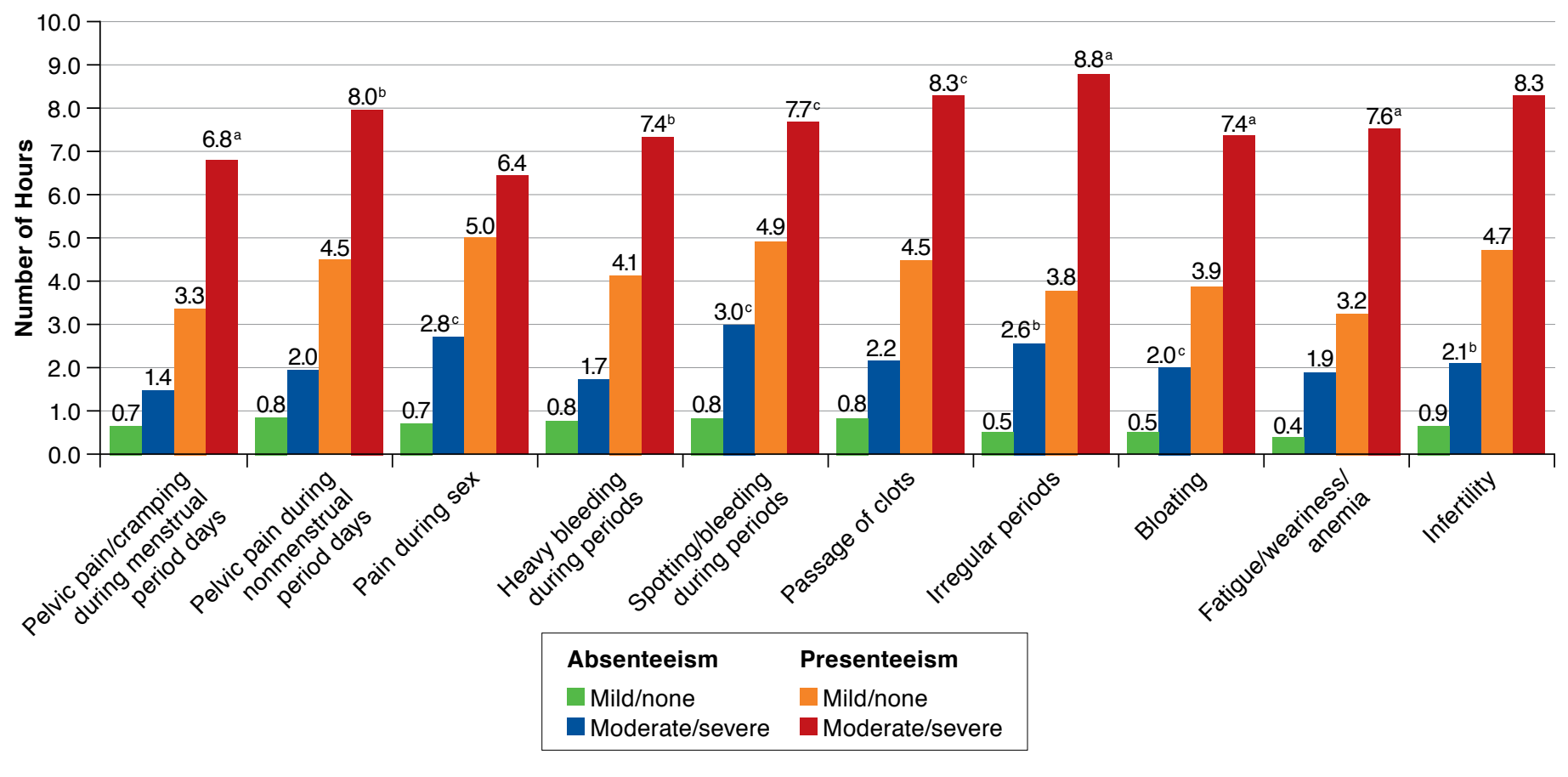

$a_{P}<0.001$

${ }^{b} P<0.01$.

${ }^{c} P<0.05$.

\section{Effect of Endometriosis on Productivity}

Women with endometriosis lost an average of 1.1 hours $(\mathrm{SE} \pm 0.2)$ of employment productivity because of absenteeism and an average of 5.3 hours ( $\mathrm{SE} \pm 0.4$ ) because of presenteeism. Percentage of effect of employment productivity lost because of absenteeism was $2.9 \%$ and $14.0 \%$ because of presenteeism (Table 2). On average, women lost a total of 6.3 work hours per week, which corresponded to $16.9 \%$ of scheduled work hours. As would be expected, participants working full time lost significantly more total hours of work (6.8 vs. 4.4 hours; $P=0.0186$ ) and percentage of time lost $(11.4 \%$ vs. $4.1 \% ; P=0.0032)$ than their part-time counterparts. Presenteeism represented $82.8 \%$ of the total productivity hours lost. Household productivity was affected to a greater extent than employment productivity. Women with endometriosis lost an average of 2.5 hours ( $\mathrm{SE} \pm 0.2$ ) of household productivity as a result of absenteeism and 2.3 hours ( $\mathrm{SE} \pm 0.2$ ) as a result of presenteeism. Percentage of effect of household chores time lost (in hours) was 15.2\% as a result of absenteeism and $12.7 \%$ as a result of presenteeism.

Younger women (aged 18-29 years) reported significantly greater losses in employment presenteeism than their older counterparts (aged 40-44 years; 6.6 hours vs. 2.8 hours,
$P=0.001$ ). The $40-44$ years age group also lost a significantly lower number of total hours of employment productivity (3.2 hours, $P=0.002$ ), compared with the $18-29$ years age group (8.0 hours, $P=0.002$ ). Similar findings were noted for household chore productivity.

Employment hours that were lost because of absenteeism were significantly higher for women experiencing moderate/ severe pain during sex, pelvic pressure, lower back pain, irregular bleeding, bloating, fatigue/weariness/anemia, and general abdominal pain compared with women who reported mild/no symptoms (Figure 1). The number of presenteeism hours lost was generally higher than hours lost to absenteeism, and more hours were lost by women with moderate/severe symptoms in comparison with those with mild/no symptoms for all symptoms assessed, with the exception of pain during sex, spotting/ bleeding between periods, and infertility (Figure 1).

Hours of household productivity lost because of absenteeism were significantly higher for women who currently experienced moderate/severe symptoms compared with women reporting mild/no symptoms, respectively: pelvic pain/cramping during menstrual period (3.6 vs. 1.1; $P<0.0001$ ); pelvic pain during nonmenstrual period days (4.6 vs. $1.8, P<0.0001$ ); pain 


\section{FIGURE 2 Hours of Lost Employment and Household Productivity by Levels of Patient-Reported} Overall Severity of Endometriosis Symptoms

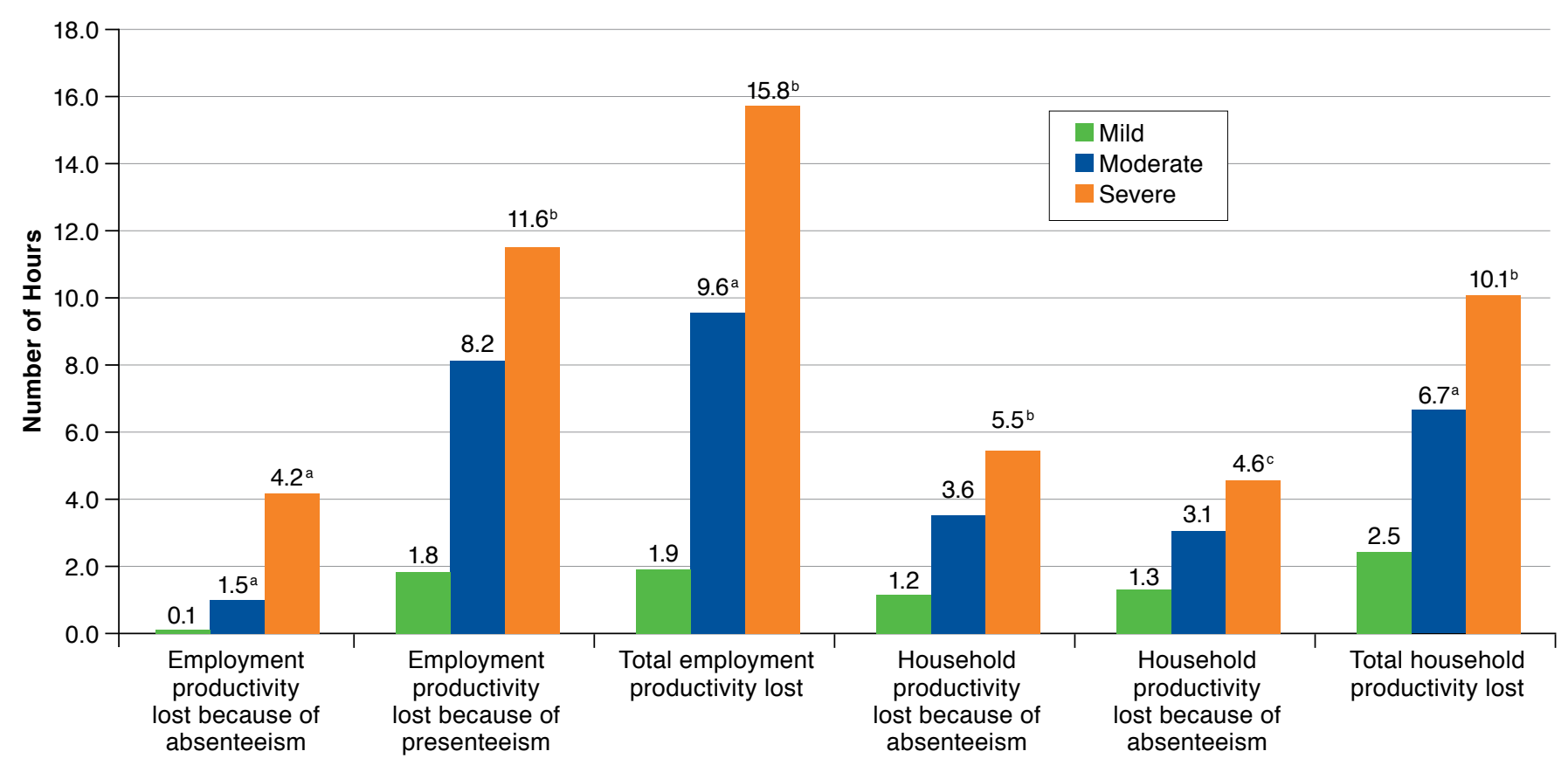

a Moderate vs. severe, $P<0.05$.

${ }^{b}$ Mild vs. severe, $P<0.0001$.

${ }^{c}$ Mild vs. severe, $P<0.01$.

during sex (4.6 vs. 2.0, $P<0.001$ ); heavy bleeding during periods (3.5 vs. $1.9, P<0.001$ ); spotting/bleeding between periods (5.2 vs. $2.1, P<0.01$ ); passage of clots (3.6 vs. $2.2, P<0.001$ ); irregular periods (4.4 vs. $1.9, P<0.001$ ); bloating ( 4.0 vs. $1.5, P<0.0001$ ); and fatigue/weariness/anemia (3.9 vs. 1.1, $P<0.0001)$

Hours of household productivity lost because of presenteeism were significantly higher for women who currently experienced moderate/severe symptoms compared with women reporting mild/no symptoms, respectively: pelvic pain/cramping during menstrual period (3.2 vs. $1.1 ; P<0.0001$ ); pelvic pain during nonmenstrual period days (3.1 vs. 2.1, $P<0.05$ ); heavy bleeding during periods ( 3.4 vs. $1.6, P<0.001$ ); passage of clots (4.1 vs. 1.8, $P<0.01$ ); irregular periods (3.3 vs. 2.0, $P<0.05$ ); bloating (3.0 vs. $1.9, P<0.05$ ); and fatigue/weariness/ anemia (3.2 vs. $1.5, P<0.0001)$. Similar findings were observed in employment productivity as measured by absenteeism and presenteeism (Figure 1).

There were significantly greater losses in employment and household chore productivity because of absenteeism and presenteeism in women reporting overall severe endometriosis symptoms compared with those reporting mild symptoms
$(P<0.01$; Figure 2). Significant differences were also present in employment productivity lost because of absenteeism and total hours of employment and household chore productivity lost $(P<0.05)$ between participants who experienced moderate and severe symptoms.

Employed women experienced a mean of 4.9 symptoms and 1.5 endometriosis symptoms, and women in the overall sample experienced 5.1 symptoms and 1.5 endometriosis symptoms. As the number of endometriosis symptoms increased, the greater the effect on hours of employment and household productivity lost overall and because of absenteeism and presenteesim (Appendix B, available in online article). As expected, participants who experienced 3 endometriosis symptoms concurrently (menstrual pelvic pain/cramping, nonmenstrual pelvic pain, and pain during sex) lost a significantly greater number of employment and household chore hours because of absenteeism and presenteeism compared with those who reported experiencing none, 1 , or 2 symptoms.

Logistic regression analyses showed that ethnicity (i.e., other vs. white Caucasian), body mass index, pain during sex, irregular periods, and general abdominal pain were significantly associated with employment time lost because of absenteeism. 
TABLE 3 Logistic Regression Analyses of the Predictors of Absenteeism or Presenteeism for Household Chore and Employment Productivity Loss

\begin{tabular}{|c|c|c|c|c|c|c|c|c|}
\hline \multirow{3}{*}{$\begin{array}{l}\text { Predictors } \\
\text { Age }\end{array}$} & \multicolumn{4}{|c|}{$\begin{array}{l}\text { Household Chore Productivity Loss } \\
\text { OR }(95 \% \text { CI })\end{array}$} & \multicolumn{4}{|c|}{$\begin{array}{c}\text { Employment Productivity Loss } \\
\text { OR }(95 \% \mathrm{CI})\end{array}$} \\
\hline & \multicolumn{2}{|c|}{ Absenteeism } & \multicolumn{2}{|c|}{ Presenteeism } & \multicolumn{2}{|c|}{ Absenteeism } & \multicolumn{2}{|c|}{ Presenteeism } \\
\hline & 1.0 & $(0.9-1.0)$ & 1.0 & $(1.0-1.0)$ & 1.0 & $(0.9-1.0)$ & $1.0^{\mathrm{b}}$ & $(0.9-1.0)$ \\
\hline \multicolumn{9}{|l|}{ Ethnicity ${ }^{a}$} \\
\hline Black African American & 1.2 & $(0.5-2.9)$ & 1.1 & $(0.5-2.3)$ & 0.3 & $(0.0-2.4)$ & 0.8 & $(0.3-2.4)$ \\
\hline Other & 1.0 & $(0.5-2.0)$ & 1.1 & $(0.6-1.9)$ & $3.1^{\mathrm{c}}$ & $(1.1-9.0)$ & 1.2 & $(0.6-2.2)$ \\
\hline \multicolumn{9}{|l|}{ Education $^{a}$} \\
\hline$<$ High school & $1.7^{\mathrm{c}}$ & $(0.9-3.2)$ & $2.7^{c}$ & $(1.5-4.7)$ & 1.4 & $(0.3-7.2)$ & 2.2 & $(1.0-5.0)$ \\
\hline Some college/college & $0.8^{\mathrm{c}}$ & $(0.5-1.3)$ & 1.3 & $(0.9-2.0)$ & 0.5 & $(0.2-1.3)$ & 1.3 & $(0.9-2.1)$ \\
\hline \multicolumn{9}{|l|}{ U.S. region ${ }^{a}$} \\
\hline Midwest & 1.0 & $(0.6-1.7)$ & 1.1 & $(0.6-1.9)$ & 1.2 & $(0.4-3.2)$ & 1.4 & $(0.7-2.6)$ \\
\hline Northeast & 0.7 & $(0.4-1.2)$ & 0.7 & $(0.4-1.2)$ & 0.3 & $(0.1-1.2)$ & 0.9 & $(0.5-1.8)$ \\
\hline South & 0.8 & $(0.5-1.5)$ & 0.8 & $(0.5-1.3)$ & 1.1 & $(0.4-2.7)$ & 1.3 & $(0.7-2.3)$ \\
\hline \multicolumn{9}{|l|}{ Marital status ${ }^{a}$} \\
\hline Married or civil union & 0.8 & $(0.5-1.3)$ & 0.9 & $(0.6-1.4)$ & 0.9 & $(0.4-2.0)$ & 1.3 & $(0.8-2.0)$ \\
\hline Body mass index & 1.0 & $(1.0-1.0)$ & 1.0 & $(1.0-1.1)$ & $1.1^{\mathrm{b}}$ & $(1.0-1.1)$ & 1.0 & $(1.0-1.0)$ \\
\hline \multicolumn{9}{|l|}{ Symptoms } \\
\hline Pelvic pain/cramping during menstrual period & $2.6^{\mathrm{c}}$ & $(1.7-3.9)$ & $2.5^{\mathrm{c}}$ & $(1.8-3.5)$ & 1.6 & $(0.6-3.9)$ & $2.4 \mathrm{~d}$ & $(1.5-3.6)$ \\
\hline Pelvic pain during nonmenstrual period days & 1.3 & $(0.8-2.1)$ & $1.8^{\mathrm{c}}$ & $(1.2-2.7)$ & 0.8 & $(0.3-2.2)$ & $2.0^{\mathrm{b}}$ & $(1.7-3.6)$ \\
\hline Pain during sex & 1.3 & $(0.7-2.2)$ & 1.1 & $(0.6-1.8)$ & $2.7 \mathrm{c}$ & $(1.2-6.5)$ & $1.9^{\mathrm{c}}$ & $(1.0-3.8)$ \\
\hline Spotting/bleeding between periods & 0.8 & $(0.5-1.4)$ & 1.2 & $(0.7-2.2)$ & 0.8 & $(0.3-2.0)$ & 0.8 & $(0.4-1.7)$ \\
\hline Irregular periods (timing and/or duration) & 1.5 & $(1.0-2.3)$ & 0.9 & $(0.6-1.3)$ & $3.7^{b}$ & $(1.6-8.4)$ & $1.9^{\mathrm{c}}$ & $(1.1-3.3)$ \\
\hline Pelvic pressure & 1.5 & $(0.8-2.6)$ & 1.0 & $(0.5-1.9)$ & 0.8 & $(0.3-2.2)$ & 0.7 & $(0.3-1.6)$ \\
\hline Lower back pain & 1.3 & $(0.9-1.9)$ & 1.1 & $(0.7-1.6)$ & 1.8 & $(0.8-4.0)$ & 1.4 & $(0.9-2.1)$ \\
\hline General abdominal pain & 1.3 & $(0.8-2.2)$ & 1.1 & $(0.7-1.7)$ & $3.5^{\mathrm{b}}$ & $(1.6-7.6)$ & $2.8^{\mathrm{b}}$ & $(1.4-5.5)$ \\
\hline Bloating & $1.6^{\mathrm{c}}$ & $(1.0-2.4)$ & $1.7^{\mathrm{c}}$ & $(1.1-2.4)$ & 0.7 & $(0.3-1.7)$ & 1.2 & $(0.7-2.0)$ \\
\hline Fatigue/weariness/anemia & $1.6^{\mathrm{c}}$ & $(1.1-2.4)$ & 1.3 & $(0.9-1.9)$ & 1.2 & $(0.6-2.7)$ & 1.5 & $(1.0-2.4)$ \\
\hline Infertility & 1.0 & $(0.5-1.9)$ & 1.1 & $(0.7-1.9)$ & 1.7 & $(0.7-4.2)$ & 0.8 & $(0.5-1.5)$ \\
\hline \multicolumn{9}{|l|}{ Comorbid conditions } \\
\hline Diabetes & 0.8 & $(0.4-1.8)$ & 1.7 & $(0.7-3.9)$ & 0.8 & $(0.2-2.7)$ & 2.2 & $(0.9-5.4)$ \\
\hline Irritable bowel disease or inflammatory bowel disease & 0.8 & $(0.5-1.3)$ & 0.9 & $(0.6-1.4)$ & 2.0 & $(0.9-4.3)$ & 1.0 & $(0.6-1.7)$ \\
\hline Fibromyalgia & 1.6 & $(0.8-3.0)$ & 1.7 & $(0.9-3.5)$ & 0.8 & $(0.3-2.5)$ & 1.8 & $(0.7-4.5)$ \\
\hline Ovarian cysts & $1.7 \mathrm{c}$ & $(1.2-2.6)$ & 0.9 & $(0.6-1.2)$ & 0.8 & $(0.4-1.8)$ & 0.7 & $(0.5-1.2)$ \\
\hline Depression & 1.3 & $(0.9-1.9)$ & 1.2 & $(0.8-1.7)$ & 1.0 & $(0.5-2.1)$ & $1.9^{\mathrm{c}}$ & $(1.2-3.1)$ \\
\hline Hypertension or high blood pressure & 1.6 & $(1.0-2.8)$ & $1.8^{\mathrm{c}}$ & $(1.1-2.9)$ & 1.4 & $(0.6-3.3)$ & $2.0^{c}$ & $(1.0-3.7)$ \\
\hline Chronic fatigue syndrome & 1.1 & $(0.5-2.4)$ & 0.5 & $(0.2-1.2)$ & 1.4 & $(0.4-4.2)$ & 0.6 & $(0.3-1.3)$ \\
\hline Interstitial cystitis & 1.1 & $(0.5-2.4)$ & 0.8 & $(0.3-2.2)$ & 1.0 & $(0.2-6.3)$ & 2.5 & $(0.7-9.3)$ \\
\hline \multicolumn{9}{|c|}{ 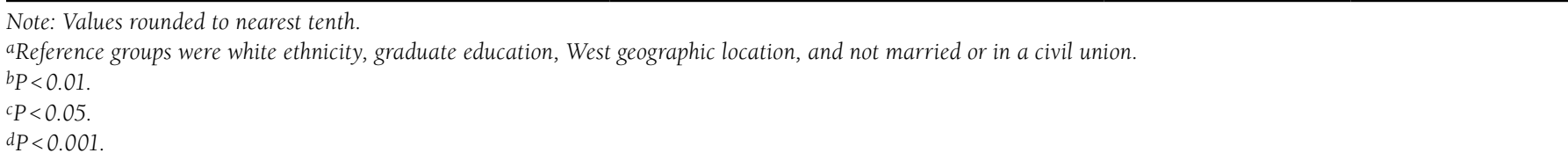 } \\
\hline
\end{tabular}

Additional variables were associated with employment time lost because of presenteeism, including younger age, pelvic pain/cramping during menstrual period and nonmenstrual period days, pain during sex, irregular periods, and general abdominal pain. Of the comorbid conditions, depression and hypertension were significantly associated with employment time lost because of presenteeism (Table 3). Women with a high school education or less were more likely to report household chores time lost because of absenteeism and presenteeism compared with women with a graduate education (Table 3). In addition, women with pelvic pain/cramping during menstrual period, bloating, fatigue/weariness/anemia, and the presence of ovarian cysts were more likely to report household chores time lost because of absenteeism, and women with pelvic pain/cramping during menstrual period, pelvic pain during nonmenstrual period days, bloating, and hypertension were more likely to report household chore time lost because of presenteeism (Table 3). 


\section{Discussion}

This study demonstrated the association of individual endometriosis symptoms with employment and household chore productivity as measured by absenteeism and presenteeism in a population survey of women with endometriosis. To the authors' knowledge, this is the first study to examine the effect of specific individual symptoms on employment and household productivity among women with endometriosis. Little has been known about the effect of individual symptoms and symptom severity on household and housekeeping activities of women with endometriosis.

The findings of the present study are consistent with past research, which has shown that symptoms such as general abdominal pain and comorbid conditions (e.g., depression) can have a negative effect on work productivity. ${ }^{5,9,13,14}$ Together, these findings indicate that an increase in the number of symptoms can lead to significant employment and household productivity loss in women with endometriosis. Pelvic pain/ cramping was the most commonly reported symptom, but the effect on productivity was not limited to these symptoms alone. Other symptoms of endometriosis, such as nonmenstrual pelvic pain/cramping and pain during sex, seem to play an independent role in productivity loss because of endometriosis as well. Furthermore, women who rate their symptoms as moderate/severe experience greater employment and household chore productivity loss, compared with women who rate their symptoms as none/mild. More severe symptoms lead to greater productivity loss in women with endometriosis.

Nnoaham et al. (2011) also reported that overall work productivity loss for women with endometriosis was 10.8 hours per week $(\mathrm{SD}=12.2){ }^{9}$ In the present study, women with endometriosis lost an average of 1.1 hours of employment productivity because of absenteeism and an average of 5.3 hours because of presenteeism in the week before survey administration. The disparate study populations may help to explain the differences in productivity losses, since only women scheduled for a laparoscopy were included in Nnoaham et al.'s study, which included 93 women only from the United States, whereas the present study was a community-based sample of women who reported being diagnosed with or being treated for endometriosis. ${ }^{9}$ Importantly, in Nnoaham et al.'s study, the women were asked about their absenteeism and presenteeism 1 week before their scheduled surgery, which may not be reflective of true work patterns, since women may have had to take more time off to attend clinic appointments and/or to prepare for upcoming surgery. ${ }^{9}$ Generally, women scheduled for surgery to treat their endometriosis have more severe symptoms, whereas the current study included some women without symptoms (16\%).

Comparatively, the absenteeism figures for employed women in this study are lower than those reported in previous studies.
Fourquet et al. found that their sample of 107 symptomatic women reported missing a mean of 2.8 days per month, which is equivalent to 33.6 days per year. ${ }^{5}$ On average, our findings indicated that 6.6 days per annum are lost because of absenteeism, which is substantially lower than what Fourquet et al. noted. ${ }^{5}$ While these samples are similar in age and symptoms, the location of the participants (United States vs. Puerto Rico) could be an important factor in explaining the difference. In addition, recall periods of productivity lost may have differed, although this is not reported by Fourquet et al. ${ }^{5}$ One last factor that could have contributed to the observed differences is the differing sample sizes between the Fourquet study and the present study. Nevertheless, $27.9 \%$ of total household and $16.9 \%$ of total employment productivity was lost because of endometriosis in the present study. Together, these findings indicate that absenteeism is likely to occur to some degree and that endometriosis disrupts all areas of women's daily lives. ${ }^{2,5}$ In comparison with other conditions, women with endometriosis have reported greater work productivity and activity impairment than patients with conditions such as rheumatoid arthritis. ${ }^{1}$ Furthermore, the absenteeism rates reported in this study are higher than those reported for other pain conditions such as headaches and back pain. ${ }^{25}$

Regression analysis showed that bleeding and nonbleeding symptoms predicted employment time lost because of absenteeism and presenteeism, although a larger number of variables predicted presenteeism. The relatively high levels of presenteeism in this study indicate that women with endometriosis make an effort to be present at work despite their symptom experience, which likely leads to impaired work productivity. Some women may not inform their employers of their endometriosis for a variety of reasons, including the difficulty in discussing a gender-specific condition with male employers. ${ }^{26}$ Moradi et al. (2014) found that some women were forced to work even when their symptoms were severe because they found it difficult to take time off from work. ${ }^{3}$ Women who do not have understanding employers may have more negative experiences and face threats of losing their jobs. ${ }^{3}$

Importantly, women attending work with poor health status has negative financial implications for women and their employers. On average, the results of this study indicated that 6.6 days per annum are lost because of absenteeism, and 31.8 days per annum are unproductive days at work. Using the 2014 average total compensation of $\$ 33.13$ per hour, ${ }^{27}$ the annual absenteeism cost per person is $\$ 1,749.26$ (assuming a period of 48 weeks per year). ${ }^{28}$ The total number of annual unproductive (presenteeism) days cost $\$ 8,428.27$ per person (also assuming a period of 48 weeks per year), so the total loss (absenteeism and presenteeism) is approximately $\$ 10,177.54$ per year. 
Applying the most commonly reported prevalence of endometriosis (10\%) to the total number of the employed U.S. female population aged $18-49$ years in $2014(44,614,000),{ }^{29}$ the total loss (absenteeism and presenteeism) would be approximately $\$ 45.4$ billion annually. Such an estimate could be viewed as conservative, since some researchers have advocated for using multipliers (i.e., defined as the cost to an employer of an absence as a proportion of the absent worker's daily wage) when measuring the indirect cost burden. ${ }^{28,30}$ Applying an average multiplier of 1.61, the indirect cost burden of endometriosis in the United States would amount to $\$ 73.1$ billion. ${ }^{30}$

Previous research has shown that endometriosis places a significant economic burden on society and resources. A retrospective questionnaire-based survey to measure endometriosis costs in 12 tertiary care centers in 10 countries (Belgium, Denmark, France, Germany, Hungary, Italy, Netherlands, Switzerland, the United Kingdom, and the United States) found that the average annual total societal cost per woman related to endometriosis (including direct and indirect costs) was $\$ 16,116$ (95\% confidence interval $=\$ 15,130-\$ 17,101){ }^{7}$ The costs of productivity loss (including work absence/reduced productivity at work) was calculated as $\$ 13,048$ per woman. Furthermore, total annual burden of endometriosis symptoms, defined as direct costs and indirect costs, varied widely, from $\$ 2$ billion in Denmark to $\$ 119$ billion in the United States, but the health care costs were related to hospitalization (32\%), monitoring tests (26\%), physician visits (24\%), and medication (7\%) and may underestimate the indirect cost burden. D'Hooghe et al. (2011) reported that the indirect costs of productivity loss are similar to those of other chronic conditions, such as ankylosing spondylitis (66\% of total costs) and rheumatoid arthritis (57\% of total costs). ${ }^{13}$

These findings are useful in creating awareness of the effect of endometriosis on employees so that employers can take steps to understand, support, and manage their employees' health condition appropriately. ${ }^{2}$ De Graaff et al. (2013) recommended the development of strategies that provide guidance for women and employers to find ways to manage endometriosis symptoms while at work, in order to reduce absenteeism and presenteeism rates. ${ }^{4}$ Overall, women with endometriosis need better support, understanding, and acceptance of their condition from their employers without the fear of negative consequences.

\section{Limitations}

This study provides a much-needed insight into how endometriosis affects the productivity of employed and unemployed women from the patient perspective, which provides crucial inputs to the overall societal burden of endometriosis in the
United States. However, study limitations require discussion, some of which have been previously reported..$^{22}$ First, regarding the online survey, only women who had access to the internet were able to participate. This sample of women may have been more inclined to discuss their health status and individual symptoms compared with women who did not have access to the internet and those who chose not to participate in the survey.

Second, all responses, including diagnosis, medication use, current symptoms, and work loss data, were self-reported and could not be verified, thereby introducing a level of response bias in the data. Recall and reporting errors may have also occurred, especially when trying to remember the details of the number of work and household hours missed. Although an objective verification of employment records would be a more accurate way of measuring absenteeism, self-reporting allows the respondent to attribute the missed work to a specific condition or reason. In addition, online surveys are an efficient way of capturing presenteeism, which may not be possible using other methods. Finally, this analysis focused on overall disease burden, regardless of the type of treatment received, so the effect of different treatment types on reducing the endometriosis burden of health-related productivity was not accounted for in the regression models.

Some points about the instrument used to measure absenteeism and presenteeism are also noteworthy. The HRPQ has good construct and criterion validity, but the reliability has not been tested. ${ }^{24}$ Further research and psychometric testing of this instrument is needed to test the reproducibility of the measure. Notwithstanding the limitations, the present study provides an important contribution in further understanding the effect of endometriosis on employment and household productivity losses.

\section{Conclusions}

This study demonstrates a significant relationship between the patient-reported type and severity of endometriosis symptoms experienced and the overall employment and household productivity losses because of absenteeism and presenteesim. A number of symptoms were found to significantly predict the likelihood of employment or household productivity loss: pelvic pain/cramping during menstrual period, pelvic pain during nonmenstrual period days, pain during sex, irregular periods, general abdominal pain, bloating, and fatigue/weariness/anemia. Total productivity loss appears to be driven mainly by presenteeism. Total productivity loss in employed women was 6.3 hours per week, with endometriosis contributing to losing $16.9 \%$ of employment productivity. The findings indicate a need for guidance strategies to help women and employers manage endometriosis in order to reduce productivity loss. 


\section{Authors}

AHMED M. SOLIMAN, MS, PhD; JANE CASTELLI-HALEY, PhD; and MICHAEL C. SNABES, MD, PhD, AbbVie, North Chicago, Illinois. KARIN S. COYNE, MPH, PhD, Evidera-Evidence, Value $\&$ Access by PPD, Bethesda, Maryland; KATHARINE S. GRIES, PharmD, PhD, Evidera-Evidence, Value \& Access by PPD, Seattle, Washington; and ERIC S. SURREY, MD, Colorado Center for Reproductive Medicine, Lone Tree, Colorado.

AUTHOR CORRESPONDENCE: Ahmed M. Soliman, MS, PhD, Health Economics and Outcomes Research, AbbVie, D-GMH1, AP31-1, 1 N. Waukegan Rd., North Chicago, IL 60064. Tel.: 847.938.5475; E-mail: ahmed.m.soliman@abbvie.com.

\section{DISCLOSURES}

The design and financial support for this study was provided by AbbVie. AbbVie participated in data analysis, interpretation of data, review, and approval of the manuscript. Coyne and Gries are employees of EvideraEvidence, Value \& Access by PPD and were paid scientific consultants for AbbVie in connection with this study. Soliman, Castelli-Hayley, and Snabes are AbbVie employees and may own AbbVie stock or stock options. Surrey is affiliated with Colorado Center for Reproductive Medicine and was paid by AbbVie as a consultant for this project. Surrey serves as a consultant for AbbVie outside of this project. All authors participated in data analysis and interpretation, and contributed to the development of the manuscript. The authors maintained control over the final contents of the manuscript and the decision to publish.

Study concept and design were contributed by Soliman, Coyne, Gries, and Castelli-Haley. Soliman, Castelli-Haley, Coyne, and Gries collected the data, and data interpretation was performed by Snabes, Surrey, Soliman, Coyne, and Gries. The manuscript was written and revised by Soliman, Coyne, and Gries, along with the other authors.

\section{ACKNOWLEDGMENTS}

Medical writing services were provided by Savita Anand, PhD, of EvideraEvidence, Value \& Access by PPD, and were funded by AbbVie.

\section{REFERENCES}

1. Fourquet J, Báez L, Figueroa M, Iriarte RI, Flores I. Quantification of the impact of endometriosis symptoms on health-related quality of life and work productivity. Fertil Steril. 2011;96(1):107-12.

2. Culley L, Law C, Hudson N, et al. The social and psychological impact of endometriosis on women's lives: a critical narrative review. Hum Reprod. 2013;19(6):625-39.

3. Moradi M, Parker M, Sneddon A, Lopez V, Ellwood D. Impact of endometriosis on women's lives: a qualitative study. BMC Womens Health. 2014;14(1):123.

4. De Graaff A, D'Hooghe T, Dunselman G, et al. The significant effect of endometriosis on physical, mental and social wellbeing: results from an international cross-sectional survey. Hum Reprod. 2013;28(10):2677-85.

5. Fourquet J, Gao X, Zavala D, et al. Patients' report on how endometriosis affects health, work, and daily life. Fertil Steril. 2010;93(7):2424-28.

6. Bokor A, Koszorús E, Brodszky V, D’Hooghe T, Consortium WE, Rigó J. The impact of endometriosis on quality of life in Hungary. Orv Hetil. 2013;154(36):1426-34.

7. D'Hooghe T, Dirksen C, Dunselman G, de Graaff A, Simoens S, Consortium WE. The costs of endometriosis: it's the economy, stupid. Fertil Steril. 2012;98(3):S218-S219.

8. Nnoaham K, Sivananthan S, Hummelshoj L, et al. Global study of women's health: a multi-centre study of the global impact of endometriosis. Paper presented at: 26th Annual Meeting of European Society of Human Reproduction and Embryology; Rome, Italy; June 27-30, 2010.
9. Nnoaham KE, Hummelshoj L, Webster P, et al. Impact of endometriosis on quality of life and work productivity: a multicenter study across ten countries. Fertil Steril. 2011;96(2):366-373.e8.

10. Nnoaham KE, Sivananthan S, Hummelshoj L, et al. Multi-centre studies of the global impact of endometriosis and the predictive value of associated symptoms. J Endometr. 2009;1(1):36.

11. Hummelshoj L. I151 Worldwide studies have proven the challenge of endometriosis, its impact, and global costs. Int J Gynaecol Obstet. 2012;119:S197.

12. Mathias SD, Kuppermann M, Liberman RF, Lipschutz RC, Steege JF. Chronic pelvic pain: prevalence, health-related quality of life, and economic correlates. Obstet Gynecol. 1996;87(3):321-27.

13. D'Hooghe T, Hummelshoj L, Dunselman G, Dirksen C, Simoens S, Consortium WE. The societal burden of endometriosis equals that of other chronic diseases: a prospective international study of costs. Hum Reprod. 2011;26(Suppl 1):i206-i207 [Abstract P-215]. Available at: https://insights. ovid.com/human-reproduction/hurep/2011/09/001/215-societal-burdenendometriosis-equals-chronic/596/00004683. Accessed May 20, 2017. 14. Simoens S, Dunselman G, Dirksen C, et al. The burden of endometriosis: costs and quality of life of women with endometriosis and treated in referral centres. Hum Reprod. 2012;27(5):1292-99.

15. Boström P, Lövkvist L, Gustafsson M, et al. Cost of illness in women with endometriosis. Value Health. 2012;15(7):A538 [Abstract PIH14]. Available at: http://www.valueinhealthjournal.com/article/S1098-

3015(12)03599-1/fulltext. Accessed May 20, 2017.

16. Gao X, Outley J, Botteman M, Spalding J, Simon JA, Pashos CL. Economic burden of endometriosis. Fertil Steril. 2006;86(6):1561-72.

17. Klein S, D'Hooghe T, Meuleman C, Dirksen C, Dunselman G, Simoens S. What is the societal burden of endometriosis-associated symptoms? A prospective Belgian study. Reprod Biomed Online. 2014;28(1):116-24.

18. Levy AR, Osenenko KM, Lozano-Ortega G, et al. Economic burden of surgically confirmed endometriosis in Canada. J Obstet Gynaecol Can. 2011;33(8):830-37.

19. Prast J, Oppelt P, Shamiyeh A, Shebl O, Brandes I, Haas D. Costs of endometriosis in Austria: a survey of direct and indirect costs. Arch Gynecol Obstet. 2013;288(3):569-76.

20. Simoens S, Hummelshoj L, D'Hooghe T. Endometriosis: cost estimates and methodological perspective. Hum Reprod. 2007;13(4):395-404.

21. Wasiak R, Hjalte F, Tennvall GR, Olovsson M. Cost of illness for endometriosis in Sweden. Int J Gynaecol Obstet. 2012;119(3):S553 [Abstract M067].

22. Fuldeore MJ, Soliman AM. Prevalence and symptomatic burden of diagnosed endometriosis in the United States: national estimates from a crosssectional survey of 59,411 women. Gynecol Obstet Invest. November 8, 2016 [Epub ahead of print].

23. Soliman A, Coyne K, Zaiser E, Castelli-Haley J, Fuldeore M. The burden of endometriosis symptoms on health-related quality of life in women in the United States: a cross-sectional study. J Psychosom Obstet Gynaecol. Published online February 17, 2017

24. Tundia N, Hass S, Fuldeore M, et al. Validation and U.S. population norms of health-related productivity questionnaire. Value Health. 2015;3(18):A24 [Abstract PRM82]. Available at: http://www.valueinhealthjournal.com/article/S1098-3015(15)00205-3/abstract. Accessed May 20, 2017. 25. Stewart WF, Ricci JA, Chee E, Morganstein D, Lipton R. Lost productive time and cost due to common pain conditions in the U.S. workforce. JAMA. 2003;290(18):2443-54.

26. Gilmour JA, Huntington A, Wilson HV. The impact of endometriosis on work and social participation. Int J Nurs Pract. 2008;14(6):443-48.

27. U.S. Department of Labor, Bureau of Labor Statistics. News release. Employer costs for employee compensation-December 2014.

March 11 2015. Available at: https://www.bls.gov/news.release/archives/ ecec_03112015.pdf. Accessed May 20, 2017.

28. Mitchell RJ, Bates P. Measuring health-related productivity loss. Popul Health Manag. 2011;14(2):93-98.

29. U.S. Department of Labor, Bureau of Labor Statistics. Women in the labor force: a databook. BLS Reports. December 2015. Available at: https:// www.bls.gov/opub/reports/womens-databook/archive/women-in-the-laborforce-a-databook-2015.pdf. Accessed May 20, 2017.

30. Nicholson S, Pauly MV, Polsky D, Sharda C, Szrek H, Berger ML. Measuring the effects of work loss on productivity with team production. Health Econ. 2006;15(2):111-23. 
APPENDIX A Current (Past 4 Weeks) Symptom Severity Distribution

\begin{tabular}{|c|c|c|c|c|c|c|c|c|}
\hline \multirow{3}{*}{$\begin{array}{l}\text { Current Symptoms, } \mathbf{n}(\%) \\
\text { Pelvic pain/cramping during menstrual period }\end{array}$} & \multicolumn{4}{|c|}{ All Participants $(n=1,318)$} & \multicolumn{4}{|c|}{ Employed Participants $(n=810)$} \\
\hline & \multicolumn{2}{|c|}{ Mild/None } & \multicolumn{2}{|c|}{ Moderate/Severe } & \multicolumn{2}{|c|}{ Mild/None } & \multicolumn{2}{|c|}{ Moderate/Severe } \\
\hline & 624 & $(43.1)$ & 694 & $(56.9)$ & 390 & $(45.1)$ & 420 & $(54.9)$ \\
\hline Pelvic pain during nonmenstrual period days & 995 & $(74.3)$ & 323 & $(25.7)$ & 626 & $(77.8)$ & 184 & $(22.3)$ \\
\hline Pain during sex & 1,094 & $(80.2)$ & 224 & (19.8) & 688 & $(81.4)$ & 122 & $(18.6)$ \\
\hline Heavy bleeding during periods & 821 & $(59.4)$ & 497 & $(40.6)$ & 528 & $(65.1)$ & 282 & $(34.9)$ \\
\hline Spotting/bleeding between periods & 1,151 & $(85.9)$ & 167 & $(14.1)$ & 712 & $(87.6)$ & 98 & $(12.5)$ \\
\hline Passage of clots & 1,036 & $(76.8)$ & 282 & $(23.2)$ & 646 & $(79.5)$ & 164 & $(20.5)$ \\
\hline Irregular periods (timing and/or duration) & 978 & $(72.6)$ & 340 & $(27.4)$ & 598 & $(71.2)$ & 212 & $(28.8)$ \\
\hline Pelvic pressure & 1,167 & $(86.1)$ & 151 & $(13.9)$ & 724 & $(88.3)$ & 86 & $(11.7)$ \\
\hline Lower back pain & 721 & $(52.9)$ & 597 & $(47.1)$ & 471 & $(58.2)$ & 339 & $(41.8)$ \\
\hline General abdominal pain & 1,069 & $(78.9)$ & 249 & $(21.1)$ & 670 & $(80.5)$ & 140 & $(19.5)$ \\
\hline Bloating & 837 & $(59.7)$ & 481 & $(40.3)$ & 525 & $(61.1)$ & 285 & $(38.9)$ \\
\hline Difficulty having bowel movement & 1,032 & $(74.9)$ & 286 & $(25.1)$ & 635 & $(76.1)$ & 175 & $(23.9)$ \\
\hline Fatigue/weariness/anemia & 697 & $(50.5)$ & 621 & $(49.5)$ & 444 & $(53.3)$ & 366 & $(46.7)$ \\
\hline Frequent urination or urinary urgency & 1,070 & $(79.6)$ & 248 & $(20.4)$ & 675 & $(83.0)$ & 135 & $(17.0)$ \\
\hline Infertility & 1,147 & $(86.9)$ & 171 & $(13.2)$ & 697 & $(85.2)$ & 113 & $(14.8)$ \\
\hline Obesity or weight gain & 1,001 & $(74.9)$ & 317 & $(25.1)$ & 626 & $(77.2)$ & 184 & $(22.8)$ \\
\hline Depression feelings/mood swings & 822 & $(60.0)$ & 496 & $(40.0)$ & 539 & $(65.0)$ & 271 & $(35.0)$ \\
\hline Excessive hair on face or body & 1,192 & $(88.7)$ & 126 & $(11.3)$ & 737 & $(89.6)$ & 73 & $(10.4)$ \\
\hline Thinning hair on scalp & 1,225 & $(92.1)$ & 93 & $(7.9)$ & 752 & $(92.2)$ & 58 & $(7.8)$ \\
\hline Dizziness during period & 1,147 & $(85.7)$ & 171 & $(14.3)$ & 709 & $(86.3)$ & 101 & $(13.7)$ \\
\hline Anxiety/stress & 672 & $(49.2)$ & 646 & $(50.8)$ & 439 & $(53.6)$ & 371 & $(46.5)$ \\
\hline Enlargement of the lower abdomen & 1,179 & $(88.0)$ & 139 & $(12.0)$ & 731 & $(89.9)$ & 79 & $(10.1)$ \\
\hline
\end{tabular}




\section{APPENDIX B Hours of Lost Employment and Household Productivity by Number of Concurrently} Experienced Endometriosis Symptoms ${ }^{\mathrm{a}}$

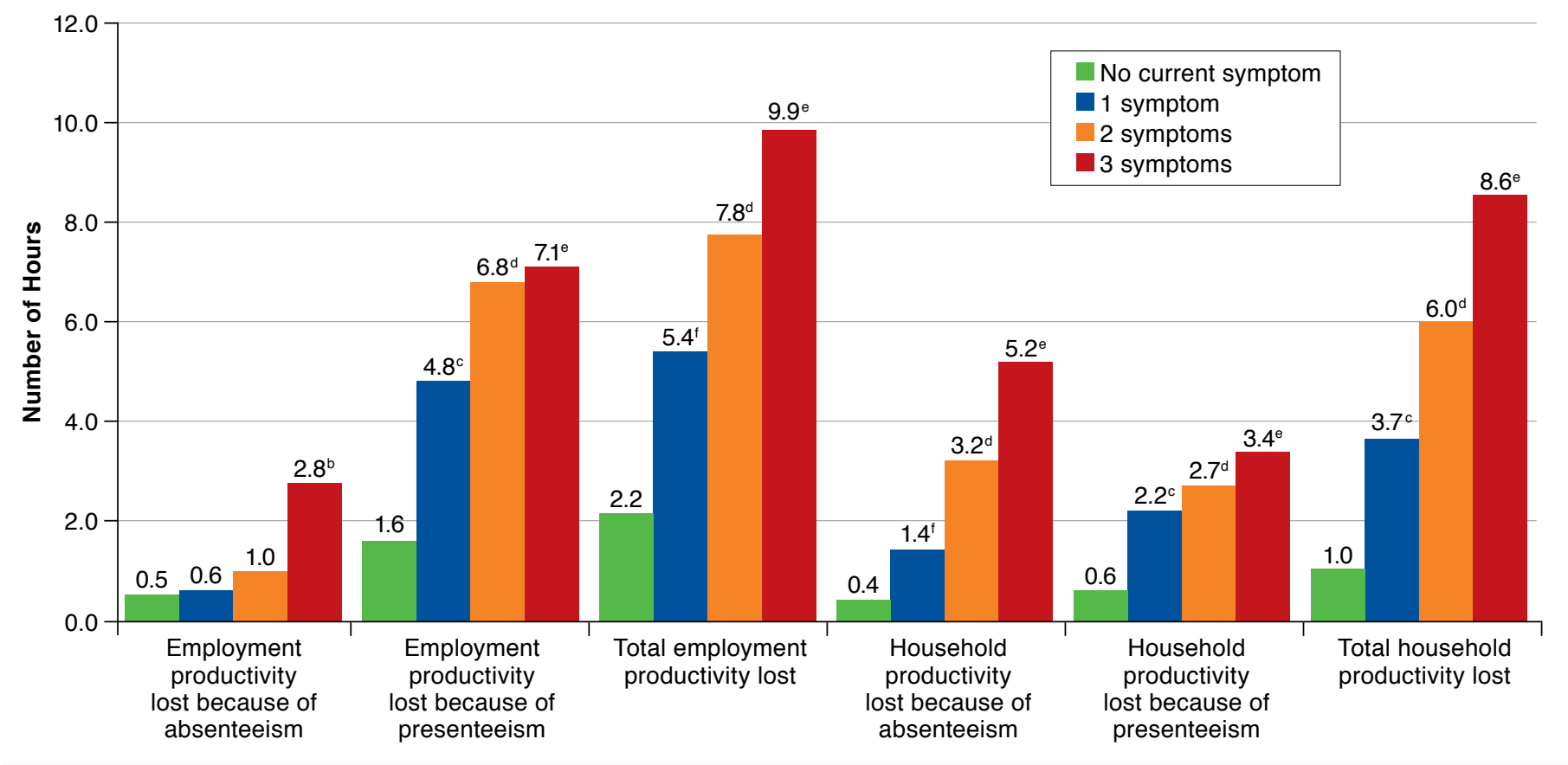

aEndometriosis symptoms included in this analysis were menstrual pelvic pain/cramping, nonmenstrual pelvic pain, and pain during sex.

bo vs. 3 symptoms, $P<0.05$.

${ }^{c} 0$ vs. 1 symptom, $P<0.001$.

do vs. 2 symptoms, $P<0.001$.

e 0 vs. 3 symptoms, $P<0.001$.

fo vs. 1 symptom, $P<0.01$. 